\title{
VI. Ergebnis zu Teil 2: Die philosophischen Grundlagen des CCM-Prinzips
}

Die philosophischen Grundlagen des CCM-Prinzips gehen auf eine breit angelegte ökologische Debatte über eine moralisch vertretbare Einstellung des Menschen zur Natur zurück, die auf theologischer, rechtlicher, ökonomischer und vor allem auf philosophischer Ebene geführt wurde und in deren Verlauf sich ein gemäßigt anthropozentrischer Ansatz herauskristallisierte, der sich letztendlich auch in den für das CCM-Prinzip wesentlichen umweltvölkerrechtlichen Dokumenten niedergeschlagen hat. ${ }^{1}$ Dieser Ansatz markiert ,,allerdings nur den vorläufigen Endpunkt einer sich permanent - teils linear, teils renaissanceartig - wandelnden Einstellung des Menschen zur Natur“, ${ }^{2}$ die lange Zeit zwischen den Extrempositionen der „,reinen“ Anthropozentrik und der Ökozentrik hin- und herschwankte, bevor sie sich gewissermaßen in eine ,geläuterte“ Anthropozentrik einpendelte. Als ethische Grundlage des common concern- Prinzips „korrigiert“ die gemäßigte Anthropozentrik im Ergebnis die rein anthropozentrischen Ansätze insofern, als sie gewissermaßen als Zugeständnis an den ökozentrischen Ansatz die Umwelt als eigenständiges Schutzobjekt anerkennt, diese aber letztendlich nicht um ihrer selbst willen, sondern in ihrer Funktion als ,elementare Lebensgrundlage des Menschen“ und damit um des Menschen willen bewahren will. Als bedeutendstes Korrektiv dient hierbei der Gedanke intergenerationeller Gerechtigkeit, der bereits bei der Entstehung des common concern-Gedankens im Beringsee-Robbenstreit im Jahr 1893 vorgetragen wurde $^{3}$ und zudem in sämtlichen für das common concern of humankind-Prinzip bedeutsamen Völkerrechtsdokumenten verankert wurde, wonach die jeweiligen Umweltgüter nicht nur für gegenwärtige, sondern auch für zukünftige Generationen der Menschheit zu schützen sind.

\footnotetext{
${ }^{1}$ Siehe Zweiter Teil, Kap. IV., S. 4 und 5.

${ }^{2}$ So Heidrich, Grundlagen des Ressourcenschutzes, S. 33.

${ }^{3}$ Ähnlich Sands/Peel, Principles, 3. Aufl., S. 209. Siehe Dritter Teil, Kap. VII. 1.
} 